\title{
O Programa de Qualificação e Desenvolvimento do Agente Comunitário de Saúde na perspectiva dos diversos sujeitos envolvidos na atenção primária em saúde The Qualification and Development Program of Community Health Agents in the perspective of the various subjects involved in primary care
}

\author{
Marilene Barros de Melo \\ Escola de Saúde Pública do Estado de Minas Gerais. Belo Horizonte, \\ MG, Brasil. \\ E-mail: marilene.meloळesp.mg.gov.br

\section{Ana Flávia Quintão} \\ Escola de Saúde Pública do Estado de Minas Gerais. Belo Horizonte, \\ MG, Brasil. \\ E-mail: anaflaviaqfœgmail.com

\section{Rose Ferraz Carmo} \\ Escola de Saúde Pública do Estado de Minas Gerais. Belo Horizonte, \\ MG, Brasil. \\ E-mail: rferrazcarmoœgmail.com
}

\section{Correspondência}

Marilene Barros de Melo

Avenida Augusto de Lima, 206I, bairro Barro Preto.

CEP 30190-002. Belo Horizonte, MG, Brasil.

\section{Resumo}

O Programa de Qualificação e Desenvolvimento do Agente Comunitário de Saúde (ACS) foi instituído pelo Ministério da Saúde visando investir em sua profissionalização. Este artigo teve por objetivo identificar, analisar e compreender as implicações do Programa de Qualificação e Desenvolvimento concluído em 2009 pela Escola de Saúde Pública do Estado de Minas Gerais na vida pessoal e laboral dos ACS e no processo de atenção à saúde, na visão dos diversos sujeitos envolvidos na Atenção Primária em Saúde (APS): ACS, equipe de Saúde da Família, gestores, docentes e usuários de 4 unidades básicas de saúde em uma capital da região Sudeste. Este estudo tem caráter qualitativo, utilizando como técnicas de coleta de informações a análise documental, entrevistas, grupo focal e questionários. As informações coletadas foram analisadas por meio da técnica de análise do discurso do sujeito e utilizando o programa SPSS, versão 16. Foram realizados 14 grupos focais com as unidades da Estratégia Saúde da Família, 4 com ACS e 4 com usuários; 7 entrevistas, 4 com gestores e 3 com docentes do curso. No grupo dos ACS, há predomínio do sexo feminino e uma baixa rotatividade. Na análise do discurso, verificou-se que o programa investigado trouxe implicações favoráveis à vida pessoal e profissional do ACS e à APS. Contudo, é necessário estruturar o programa nos parâmetros da educação permanente em saúde, assegurando uma abordagem que propicie a constru- 
ção permanente de estratégias voltadas à melhoria das condições de vida e saúde e à cidadania plena.

Palavras-chave: Profissionalização do Agente Comunitário de Saúde; Programa de Qualificação e Desenvolvimento; Atenção Primária em Saúde.

\section{Abstract}

The Development and Qualification Program for the Community Health Worker (CHW) was established by the Ministry of Health in order to invest in the Worker's professionalization. This article aimed to identify, analyze, and understand the implications of the Development and Qualification Program concluded in 2009 by the School of Public Health of the State of Minas Gerais in the personal and occupational life of the CHWs and in the health care process. According to the viewpoint of the many subjects involved in Primary Health Care (PHC): CHWs, Family Health team, managers, teachers, and users of four primary health centers in a capital city of Southeastern Brazil. This study has a qualitative nature, using as techniques for information collection and documentary analysis interviews, focus group, and questionnaires. The collected information was analyzed by means of the subject discourse analysis technique and using the software SPSS, version 16. We conducted 14 focus groups with the Family Health Strategy units, 4 with CHWs, and 4 with users; 7 interviews, 4 with managers and 3 with teachers at the course. In the Worker's group, there is a predominance of women and a low turnover. In discourse analysis, it was found that the program under study brought favorable implications to the personal and professional life of CHWs and to APS. However, it needs to start being structured on the parameters of continued health education, in order to assure an approach that provides the permanent construction of strategies aimed to improve life and health conditions and achieve full citizenship. Keywords: Professionalization of the Community Health Worker; Development and Qualification Program; Primary Health Care.

\section{Introdução}

O Ministério da Saúde (MS) tem investido fortemente na política de educação dos trabalhadores vinculados ao Sistema Único de Saúde (SUS) por meio da articulação de estratégias que envolvem a elevação do nível de escolaridade, da profissionalização e da educação permanente. Esse investimento visa fortalecer e aumentar a qualidade de resposta do setor saúde às demandas e necessidades em saúde da população.

Em relação aos Agentes Comunitários de Saúde (ACS), considerando a sua importância no contexto de mudanças de práticas de saúde e seu papel social junto às comunidades, o Departamento de Gestão da Educação na Saúde (DGES), por intermédio da Secretaria de Gestão de Trabalho e Saúde (SGTES), iniciou no primeiro semestre de 2004 uma qualificação profissional básica (Brasil, 2004). Desde então, o Programa de Qualificação e Desenvolvimento tem sido desencadeado em momentos diferentes em cada Estado, envolvendo gradualmente as três esferas de gestão do SUS.

Nos estados, esse programa fica sob a responsabilidade da Rede de Escolas Técnicas do SUS e Centros Formadores de Recursos Humanos do SUS (RET-SUS). A RET-SUS, instituída pela Portaria $\mathrm{n}^{\circ}$ 1.298, de 28 de novembro de 2000 (Brasil, 2000a), e atualizada pela Portaria $n^{0} 2.970$, de 25 de novembro de 2009 (Brasil, 2009), visa à articulação das 36 Escolas Técnicas do Sistema Único de Saúde (Etsus) de maneira a fortalecer a educação profissional do pessoal de nível médio que atua na área da saúde, qualificando-os para o desenvolvimento de ações de saúde de acordo com as demandas e necessidades no âmbito do SUS.

A Escola de Saúde Pública do Estado de Minas Gerais (ESP-MG) assumiu a qualificação de um extenso contingente de ACS. Diante dessa responsabilidade social, a ESP-MG desenvolveu uma investigação com apoio da Fundação de Amparo à Pesquisa do Estado de Minas Gerais (Fapemig) visando investigar as implicações do Programa de Qualificação e Desenvolvimento Profissional para ACS no âmbito do processo de trabalho e de atenção à saúde. Este artigo é um dos produtos dessa pesquisa, que visa identificar, analisar e compreender as implicações desse Programa, ofertado pela ESP-MG nos anos de 
2008 e 2009, na visão dos ACS, demais integrantes da equipe de saúde da família (ESF), gestores, docentes e usuários na vida pessoal e profissional dos ACS e, no âmbito dos processos de trabalho e de atenção à saúde nas UBS às quais os ACS certificados pelo curso estão vinculados.

\section{Material e método}

Este estudo é de caráter qualitativo e utilizou como técnicas de coleta dos dados a entrevista semiestruturada, o grupo focal e análise documental. Incluem-se como sujeitos da pesquisa aqueles envolvidos direta ou indiretamente no Programa de Qualificação e Desenvolvimento para ACS em quatro Unidades Básicas de Saúde (UBS) de um dos nove distritos sanitários de uma capital da Região Sudeste. 0 critério de escolha das UBS foi as que mantinham em seu quadro atual de trabalhadores o maior número de ACS egressos do Programa.

As entrevistas foram individuais e gravadas com quatro docentes de concentração do Curso e os gerentes das quatro UBS. Os grupos focais foram compostos especificamente por ACS, equipes de saúde da família que esses ACS integravam e usuários.

Em três UBS, a totalidade das equipes participou do estudo. Em uma quarta, questões operacionais relacionadas à rotina de trabalho e período de férias de alguns dos integrantes de uma das equipes impossibilitaram a realização de GF com essa equipe.

Com relação aos ACS, de 54 profissionais egressos do Programa de Qualificação, que ainda integravam o quadro de profissionais das UBS, 38 (70,4\%) participaram do estudo. A coincidência entre os dias de realização dos GF com o período de férias e licença por motivos de saúde foram motivos para a não participação dos ACS.

Utilizou-se como técnica de análise das entrevistas e grupos focais, o "Discurso do sujeito coletivo" (Lefèvre; Lefèvre, 2005), que se constitui a partir da apreensão das Idéias Centrais (IC) e respectivas Expressões Chaves (ECH) em cada relato dos diversos sujeitos da pesquisa. O conjunto das IC e ECH dão origem aos discursos-síntese - Discurso do Sujeito Coletivo (DSC). Assim, os discursos individuais são organizados em um único discurso, como se todos os depoimentos representassem um único sujeito (Lefèvre; Lefèvre, 2005).

\section{Resultados e discussão}

Em relação ao perfil dos ACS, encontrou-se um predomínio do sexo feminino - 89,5\%. Essa hegemonia está presente nos estudos de Kluthcovsky et al. (2007), Bezerra, Santo e Batista Filho (2005) e Santos et al. (2011). Esses autores encontraram uma prevalência de ACS na faixa etária de 30 a 39 anos, enquanto que os ACS desta investigação se concentravam entre 41 e 50 anos $(41,4 \%)$. O nível educacional dos ACS é o Ensino Médio completo, similar aos achados de Kluthcovsky et al. (2007), Bezerra, Santo e Batista Filho (2005) e Santos et al. (2011). No que se refere ao salário, evidenciou-se uma aproximação desta pesquisa aos valores encontrados por Kluthcovsky et al. (2007) e Santos et al. (2011), todos são abaixo de R\$̣ 1.0oo,oo.

Constatou-se que $52,4 \%$ dos ACS estão no PSF entre 3 e 4 anos, o que estabelece uma proximidade com os achados de Bezerra, Santo e Batista Filho (2005) e demonstra uma menor rotatividade desses agentes em relação à investigação de Santos et al. (2011), na qual 47,4\% estão há menos de um ano. Observou-se que 96,6\% dos ACS são efetivos e 89,7\% possui mais de um vínculo empregatício.

A apreensão das IC e ECH nos depoimentos dos ACS, usuários, gestores e demais integrantes da ESF possibilitou a elaboração dos seguintes Discursos do Sujeito Coletivo: DSC1 - o curso teve sua importância consolidada com a Lei $n^{0} 10.507$, sua estruturação e operacionalização estão sujeitas aos interesses políticos dos gestores e ainda não é socializado à comunidade; DSC2 - o referencial teórico adotado é o proposto pelo Ministério da Saúde; DSC3 - o programa trouxe mudanças no exercício profissional do ACS - fortalecimento do vínculo, empoderamento, discriminação das atribuições, profissionalização; DSC4 - o programa promoveu mudanças em relação à vida pessoal do ACS; e DSC 5 - o curso não promoveu mudanças... precisa mudar algumas coisas....

DSCI - 0 curso teve sua importância consolidada com a Lei n 10.507, sua estruturação e operacionalização estão sujeitas aos interesses políticos, dos gestores e, ainda não é socializado à comunidade.

A importância do programa foi consolidada pela Lei $n^{0} 10.507$ (Brasil, 2002). Esta lei estabeleceu o ensino fundamental completo e aprovação em uma 
qualificação básica com conteúdo programático elaborado pelo MS como condição para o exercício da função de ACS. Nessa perspectiva, não há necessidade do ACS ter conhecimento prévio em saúde para desempenhar a função. Então, o Ministério assume a responsabilidade de conceder essa qualificação a um significativo contingente de ACS. Inicialmente, o programa de qualificação, seguindo as Diretrizes Curriculares Nacionais para a Educação Profissional Técnica de Nível Médio, foi estruturado em 1.200 horas e dividido em três módulos. $O$ estado de Tocantins e a Escola Técnica em Saúde Maria Moreira da Rocha do Acre foram os únicos a concluir integralmente essa formação. $\mathrm{Na}$ maioria dos estados, apenas o primeiro módulo de formação inicial foi ofertado, em alguns locais nem a sua efetivação. Atualmente, o programa tem uma carga horária total de 400 e admite a conversão de horas de trabalho em horas de formação. Esta alteração não foi socializada, pois o discurso entre os sujeitos dessa pesquisa é estamos esperando a segunda etapa do curso, prevista pelo MS, e apontam que esta redução traz um enorme limite ao Programa. Os ACS, demais integrantes da equipe e gestores desconhecem, portanto, que a não oferta dos outros dois módulos está relacionada a uma mudança de estrutura e carga horária do programa pela SGETS, o que demarca a fragilidade no processo de publicização intrainstitucional no âmbito do SUS e compromete seriamente a gestão de educação realizada pelo MS (Brasil, 2004; Bornstein; Matta; David, 2009; Morosini, 2010).

Essa redução da carga horária tem sido associada à disputa dos diversos interesses e mediação de forças políticas, econômicas e sociais. Entre eles a oposição dos gestores, principalmente do âmbito municipal, que atuaram de maneira efetiva para que se realizasse apenas a primeira etapa formativa. Os principais motivos alegados pelos gestores são problemas com o financiamento da ação e com a formação técnica que implicaria em valores salariais mais altos, comprometendo a Lei da Responsabilidade Fiscal (Bornstein; Matta; David, 2009; Morosini, 2010).

Entre os gestores das UBS investigadas não houve consenso quanto à questão da operacionalização do processo de trabalho durante o período em que os ACS tinham que se afastar. A opinião de um deles foi que a saída dos ACS gerava alguns transtornos: [...] às vezes gerava dificuldade... trabalha-se em escala mínima... a frequência tem que ter um espaçamento maior [...] se o curso fosse hoje... eles têm outras atividades ... teríamos um impacto negativo muito grande para a unidade. Em contrapartida, outro gerente enfatizou que a saída do ACS para participar do curso não teve nenhum impacto para a comunidade, enquanto sai um o outro cobre o outro então, assim, a gente sempre procurou ter uma dinâmica para não prejudicar o usuário. As opiniões díspares das gerentes refletem questões relacionadas à organização do serviço e, de maneira mais abrangente, às questões estruturais relacionadas ao processo de trabalho das equipes de saúde da família.

Maximizar os efeitos do afastamento do ACS para a UBS exige reflexões quanto à importância da qualificação desse trabalhador, que é o primeiro profissional a ter contato com o usuário, a acompanhá-lo nas questões referentes à sua saúde, desde as ações preventivas, curativas e/ou encaminhamentos. Assume, então, uma participação fundamental para que a Atenção Primária à Saúde (APS) cumpra suas responsabilidades. A importância da ação profissional do ACS é compatível à APS que, desde a Conferência de Alma-Ata, em 1978, tem sido reconhecida como a estratégia adequada para imprimir resolutividade aos problemas de saúde de maior frequência, reduzindo danos ou sofrimentos e contribuindo para uma melhor qualidade de vida.

Segundo os gestores e a partir da análise do discurso do coletivo de usuários, esses não conseguem diferenciar a saída do ACS para curso, férias ou licença. No geral, os usuários não tinham conhecimento sobre a qualificação que o ACS tinha participado. Na visão de alguns usuários, a saída para um curso não é suficiente para justificar a ausência do ACS. No contexto do grupo focal, os usuários se posicionaram favoráveis à qualificação dos ACS e de todos os profissionais de saúde.

O desconhecimento do usuário acerca dos acontecimentos na UBS e sobre o valor do ACS, que diante dos enormes desafios no seu cotidiano laboral consegue enfrentá-los a partir de conhecimentos gerados no programa, demonstra certa fragilidade na relação comunidade/UBS, o que não é viável em um processo de atenção à saúde, que na perspectiva de 
Ceccim e Feuerwerker (2004), deve-se ter como base para a gestão das ações educativas o "quadrilátero de formação", contemplando em suas faces o ensino, a gestão, a atenção e o controle social. Todas as faces têm o mesmo valor e representam um espaço concreto de participação dos diversos sujeitos envolvidos no processo de atenção de saúde, estabelecendo critérios de relevância para a qualificação dos trabalhadores e a organização das redes de atenção, além de assegurar uma relação de interdependência com os usuários, ampliando suas possibilidades de pertencimento proativo nas decisões relacionadas ao campo da saúde.

\section{DSC2 - 0 referencial teórico adotado é o proposto pelo Ministério da Saúde}

Inicialmente, buscou-se apreender a partir do discurso coletivo dos sujeitos da pesquisa o referencial teórico que o programa investigado tem adotado. A análise do documento-“Diretrizes para Elaboração de Programas de Qualificação e Requalificação dos Agentes Comunitários de Saúde" (Brasil, 1999) buscou verificar se as competências estabelecidas pelo MS eram abordadas no curso. Evidenciou-se que as atribuições dos ACS situam-se: 1) no trabalho em equipe; 2) na visita domiciliar; 3) no planejamento das ações e serviços; 4) na prevenção e promoção da saúde; 5) no monitoramento de situações de risco e meio ambiente; 6) na prevenção e monitoramento de grupos específicos; 7) na prevenção e monitoramento de doenças prevalentes; e 8) no acompanhamento e na avaliação das ações de saúde. Essas funções foram mantidas no "Referencial Curricular para o Curso Técnico de Agente Comunitário de Saúde" publicado em 2004.

Segundo o discurso dos integrantes das ESF essas diretrizes foram acompanhadas no programa investigado:

O curso é benéfico e importante para o ACS, uma vez que o ACS chega sem bagagem nenhuma, eles assumiram a função sem nenhuma formação apenas residem na área, por isso o curso é essencial, trouxe o que é a função do ACS, promoveu maior autonomia e domínio do discurso, trouxe um outro posicionamento do ACS, uma maior compreensão do processo de trabalho, as competências como o preenchimento dos formulários; ampliou a visão, a compreensão do que é demanda social, melhorou a relação da equipe com a comunidade, passaram a encaminhar e acompanhar mais pacientes, principalmente os crônicos... um impacto grande no processo de atenção à saúde. Tem ACS que mudou com o curso, da água para o vinho.

O discurso sobre o Programa de Qualificação aponta algumas qualidades sobre a sua estruturação. Uma delas é que ele trabalha sob um enfoque problematizador baseado na construção compartilhada do conhecimento, na experiência cotidiana desses profissionais e nos princípios do SUS. Dessa forma, segundo os profissionais dá uma lapidada não somente em relação à esfera técnica, mas, também, político e social eles têm que cumprir. E, com base nisso, eles conseguem conceber o "famoso jeitinho" para a mediação adequada da UBS com a comunidade, tão importante no processo de atenção (Gomes et al., 2010).

Talvez, por essas e outras possibilidades que se abrem com a qualificação, as adequações legais em relação ao exercício profissional têm procurado contemplar as questões relacionadas à qualificação. Um dos exemplos, a Lei ${ }^{0}{ }^{0} 10.507$ (Brasil, 2002), que resultou do movimento dos ACS, por meio da Confederação Nacional dos ACS, pela luta por direitos trabalhistas e de qualificação, cria a profissão de ACS e estabelece os critérios relacionados à formação desses trabalhadores (Morosini, 2010).

Outro material de apoio utilizado como base teórica é o manual "O trabalho do agente comunitário de saúde” (Brasil, 2ooob), que apresentou um conteúdo programático baseado na concepção ampliada de saúde, nos princípios do SUS e nos conceitos de promoção da saúde e na prevenção de doenças. No âmbito da promoção da saúde, priorizou-se a concepção de risco como conceito básico e necessário na qualificação do ACS que possui como primeira ação a identificação de risco (Morosini, 2010).

Identificou-se ainda no discurso dos ACS, a demanda por conteúdos pedagógicos que priorizem "as doenças", revelando uma ancoragem ao modelo biomédico, herdeiro da racionalidade científica moderna, cuja opção pela doença exclui o sujeito e o contexto que o envolve. 
Enquanto o conteúdo programático apresentado no "Referencial Curricular para o Curso Técnico de Agente Comunitário de Saúde” (Brasil, 2004) assinala a dimensão do "saber-ser", apontada como uma ideia dos integrantes da equipe como fundamental para a prática do ACS e parece muito bem abordada no programa. 0 "saber-ser" é trabalhado na perspectiva da "produção de si" buscando capturar o que se pode chamar de subjetividade do agente, viabilizando uma formação que privilegia a capacidade crítica de refletir e opinar do ACS, que no discurso da equipe é importante devido suas atribuições irem desde uma ação técnica até a compreensão das necessidades dos usuários, muitas vezes muito mais ligadas à sua condição social. Este discurso assinala o grau de complexidade que envolve a ação do ACS, pois exige qualidades laborais e subjetivas para desenvolver ações educativas e informacionais, a visita domiciliar, ou a administração de conflitos entre a comunidade e a UBS. Entretanto, ao ressaltar o currículo por competências, o documento abre possibilidades para uma educação automatizadora, baseada na assimilação/repetição.

$\mathrm{Na}$ perspectiva do documento "Referencial Curricular para o Curso Técnico de Agente Comunitário de Saúde" (Brasil, 2004) a competência é a capacidade que se tem de reconhecer as situações e acontecimentos relacionados ao campo da saúde e de abordá-los com iniciativa e responsabilidade. Assim, estabelece como necessária uma "forte dose de imprevisibilidade e baixa margem de prescrição" (Brasil, 2004) e a qualificação profissional é a possibilidade de viabilizar o desenvolvimento de ações de saúde específicas.

Ramos (2001) enfatiza que quando a qualificação é regida apenas pela noção de competência, corre-se o risco de fragilizar suas dimensões conceitual e social e de fortalecer a dimensão experimental. Esta dimensão valoriza o aprendizado a partir das experiências do ACS, e a sua capacidade de enfrentamento das situações, advertindo que para isso ele deve ter requisitos como multifuncionalidade, flexibilidade e polivalência. Quanto à pequena valorização da dimensão conceitual, ela pode estar associada à pequena escolarização do ACS, minimizada pela sua necessidade de residir na comunidade em que trabalha. Essa situação demonstra um tratamento diferenciado para esse trabalhador em relação aos outros profissionais do campo da saúde, para os quais é destinada uma política de melhor qualificação. Essa diferença revela a concepção que se tem do trabalho do ACS: a qualificação tem relação direta com as atribuições desse trabalhador, para ele destina-se uma formação baseada na competência técnica e política, além de baixos salários. Entretanto, é necessário reconhecer a dimensão social dessa qualificação diante do empoderamento do ACS no âmbito das relações sociais desse trabalhador.

É ilusória a ideia de proximidade de uma formação ao contexto laboral cotidiano, pois este se transforma em um espaço de reprodução artificial da realidade cotidiana e se empobrece enquanto espaço de produção de conhecimento, visto que o predomínio dos conhecimentos práticos fragiliza a possibilidade de produção de novos conhecimentos. Nessa perspectiva, os trabalhadores se adaptam a sua realidade laboral e não conseguem transformá-la (Frigotto, 2006; Ramos, 2010; Monteiro; Previtali, 2011).

A introdução do currículo integrado, dos enfermeiros como facilitadores da formação e a criação de dois momentos formativos favoreceram a consolidação da integração do ensino-serviço. 0 curso analisado tem essa conformação. Um dos momentos seria caracterizado como momento de concentração, o que era realizado em sala de aula. O outro, momento de dispersão, acontece na comunidade, na microárea do agente ou na área de abrangência da UBS, este momento é a oportunidade do ACS observar de maneira mais consistente a sua realidade, refletindo e elaborando novos conceitos e consolidando sua aprendizagem (Brasil, 2004). De acordo com os docentes do curso investigado, o que os ACS trouxeram da concentração eles aplicaram na dispersão.

O Referencial Curricular de 2004 estabelece que os cursos, sempre que possível, são realizados no município de origem dos ACS. A comunidade torna-se, então, o espaço privilegiado para a formação e a prática do ACS. Entretanto, essa realidade está implicada com rotinas, cobrança de atividades e produtividade, situação não adequada para a integração da prática com o ensino. Morosini (2010) alerta que, nessa perspectiva, a dicotomia teoria/prática 
permanece, ao contrário de ser superada, pois ao se priorizar a prática (ligada ao serviço) em relação à teoria (vinculada ao ensino) é uma outra maneira de hierarquizar em uma perspectiva inversa.

A ênfase da formação em serviço constitui-se, também, como uma estratégia de que o ACS se afaste o menor tempo possível de seu trabalho. Contudo, no discurso da equipe os ACS se sentiam sobrecarregados, pressionados e cansados pela quantidade de informações e atividades. A associação - momentos de concentração e trabalho - também gerava cansaço devido à locomoção e passar do horário de trabalho. Outro discurso reforça a concepção de que apesar de todos os problemas, o curso traz benefícios ao ACS, principalmente, se considerar a fragilidade da sua inserção formal na equipe. Esta é uma realidade, uma vez que o vínculo de trabalho do ACS fragiliza a possibilidade de formação técnica para esse agente devido ao investimento temporal e financeiro e à necessidade de elevação salarial de acordo com a sua condição de técnico.

\section{$D_{3} C_{3}$ - 0 programa trouxe mudanças no exercício profissional do ACS - fortalecimento do vínculo, empoderamento, discriminação das atribuições, profıssionalização.}

A partir do discurso do sujeito coletivo dos ACS, aprendeu-se que uma das principais mudanças positivas promovidas pelo curso relaciona-se ao seu âmbito profissional, o aprendizado sobre como abordar as famílias, de forma a criar o vínculo entre eles e os usuários - Nos ensinou muito... como abordar, como lidar com as famílias, como conversar alguma coisa. Eu chamo o usuário pelo nome, então cria um vínculo maior. Assim, o curso ampliou a possibilidade de diálogo entre o ACS e o usuário/família/ comunidade, o chamar pelo nome demonstra uma proximidade, o reconhecimento do outro enquanto sujeito, consequentemente, fortalece qualquer tipo de ligação e, a vinculação entre esses dois sujeitos em torno de um objetivo que é o cuidado em saúde. Baralhas e Pereira (2011) caracterizam o vínculo como fator primordial para o processo de atenção em saúde.

Autores como Merhy (1994) e Cecílio (2001) consideram que o vínculo resulta de uma relação de confiança mútua e sustenta-se em princípios como humanização, acolhimento, comprometimento e responsabilização do profissional pelo cuidado demandado, apreendendo inclusive o "não dito". Ele assume um caráter social e seu valor terapêutico se constitui a partir do conhecimento da dinâmica social e familiar de determinado território, de suas necessidades em saúde, da possibilidade de uma atenção contínua e integral e do reconhecimento do usuário de que existe um outro comprometido em colaborar na sua luta por melhores condições de saúde. Nessa perspectiva, a instituição "SUS” passa a ocupar um lugar concreto e não integra apenas o imaginário do usuário/família/comunidade. No discurso dos ACS, constata-se que a ênfase a uma ação dialógica certamente exige uma escuta privilegiada, uma melhor qualidade da assistência e consequente fortalecimento do vínculo (Merhy, 1994, 2007; Cecílio, 2001; Lima et al., 2007).

Merhy (2007) nomeia a relação de proximidade e de diálogo entre dois sujeitos como tecnologia leve, a qual caracterizada com espaços de fala, escuta, interpretações, confiança, acolhimento e produção de vínculo, mediado pela ação do "cuidar". Essa proximidade contribui não somente em uma perspectiva técnica, mas também ético-política, privilegiando o princípio da alteridade no que concerne à solidariedade e a interdependência. Além de fortalecer a autonomia do sujeito/família/comunidade visando à busca de estratégias e decisões compartilhadas para a promoção da saúde relacionadas ao modo de viver, condições de trabalho, educação, lazer e cultura bem como para a redução de incapacidades e/ou deficiências visando à melhoria da qualidade de vida. Relaciona, ainda, um compromisso com o direito e o dever do trabalhador ACS:

O curso nos ensinou a nos resguardar também, a gente fazia coisas na rua que não era nosso compromisso. Deu mais auto confiança, hoje em dia tem uma discussão a gente pode expor o que a gente pensa. A gente se sentiu mais valorizado como profissional. O pessoal principalmente aqui dentro não valorizava o serviço da gente, né? agora hoje não... eles procuram mais a gente dão mais ouvido no que a gente fala, confia mais na gente. A amizade mesmo dentro do nosso trabalho e com as outras equipes melhorou mesmo depois do curso. 
Ter discriminadas suas atribuições significa delimitar seu campo da atuação, o que é fundamental em qualquer profissão, pois assegura seu campo de profissionalização, legitima, confere credibilidade, empodera o trabalhador na sua ação e diminui a possibilidade de sobrecarga de trabalho, em contraposição à visão romântica de que o ACS é um "super-herói”, utilizando o termo proposto por Tomaz (2002). O ACS não é responsável por toda ação desenvolvida nas famílias e na comunidade. Ter um campo de ação delimitado empodera o ACS junto à equipe e aos usuários, pois em um os discursos da equipe o ACS passou a ter voz, o que favoreceu uma ação transformadora da área a qual estão ligados, visto que se tornaram "sujeitos da ação" e não mais submissos aos desejos da equipe e dos usuários. Essa constatação vai de encontro à concepção de Freire (1978) de que não existe ação sem conhecimento.

Este conhecimento articulado às vivências do ACS na comunidade, segundo o discurso coletivo da equipe, empodera-o não somente perante aos usuários, mas também diante da equipe, legitimando a sua ação enquanto mediador população/UBS (Lotta, 2012).

O ACS é caracterizado como "elo entre a equipe de saúde e a comunidade", segundo discurso oficial do Ministério da Saúde. Isso se deve, possivelmente, ao seu contato permanente com as famílias. Portanto, o ACS ocupa uma posição de ponte entre universos culturais e saberes diferentes - o científico e o popular - facilitando o trabalho de vigilância e da promoção de saúde (Brasil, 20oob). Autores como Nogueira (2002) e Bornstein e Stotz (2008) ponderam que o papel de articulador entre quem é colocado na posição de "diferente" neutraliza a dimensão política e social da ação. Os ACS, ao visitarem os moradores da comunidade em suas casas, entram em contato com situações que estão além da capacidade de resposta do setor saúde. Isso exige deles mediações nas diversas esferas da organização da vida social para facilitar o acesso dos usuários aos direitos de cidadania. Bornstein e Stotz (2008) explicitam que a mediação assume um caráter transformador, de cooperação social, à medida que existe maior compartilhamento do conhecimento e maior permeabilidade dos serviços em relação às necessidades e demandas da população visando à superação dos problemas coletivos.
Encontrou-se em parte das equipes que o conhecimento obtido a partir do curso:

é muito bom e bem-vindo, pois traz informações importantes que são incluídas na prática por quem quer realizar trabalho com qualidade... o encaminhamento dos usuários com necessidades em saúde detectadas... o acompanhamento dos pacientes portadores de doenças crônicas... preenchimento dos formulários. O curso é um investimento que valoriza o ACS e vale a pena investir em ACS interessado pois, demonstram satisfação em se qualificar e sentem-se valorizados, mais seguros e se apoderam cada vez mais do trabalho que realizam, se tornaram sujeitos da ação... dá poder de ação ao ACS, ainda mais os que se referem às atividades curativas.

Esta afirmação demarca a formação como um valor para a ação profissional, entretanto evidencia-se uma determinação quanto ao domínio de alguns conteúdos e práticas do saber biomédico, provavelmente na acepção de que esse saber além de ser mais valorizado pela população, lhe conferiria maior status social. Essa situação sinaliza um equívoco do ACS, talvez pelo fato da qualificação lhe garantir mobilidade social ascendente, conforme Melo et al. (2009), ele não consegue perceber a importância do saber que ele traz à equipe, relacionado à dinâmica social da área em que atua, para a conformação e efetividade das intervenções biomédicas.

Nessa perspectiva, entende-se que a qualificação deve ser regida com base no referencial da saúde coletiva cujo tripé disciplinar é a epidemiologia, a gestão, política e planejamento e as ciências sociais (Paim; Almeida Filho, 200o) e nos princípios da práxis pedagógica freiriana. Esses princípios viabilizam uma interação efetiva entre as práticas pedagógicas e as relações de trabalho, em caráter dinâmico e consciente quanto ao seu processo e os objetivos a serem alcançados. Deve-se, então, a partir de uma metodologia participativa desenvolver atividades teórico-práticas em que a teoria se modifica constantemente com a experiência prática, que por sua vez transforma-se com a teoria. Nessa perspectiva, o programa de qualificação do ACS inclui tanto questões do âmbito da formação quanto do trabalho. 
A metodologia participativa do curso também foi alvo do discurso de alguns dos integrantes das equipes:

a noção que eles trouxeram de trabalhar com os ACS de maneira participativa, escutando e fazendo ações conjuntas com a equipe e até os usuários, para mudar a situação de saúde, foi tão importante que até hoje eles sempre fazem referências à elas, os ACS interessados apesar da sobrecarga do trabalho ficaram animados com essa possibilidade.

Uma qualificação que pretende se pautar em ações pedagógicas vinculadas à transformação social deve ter como norte uma perspectiva histórica e social, para compreender as relações que serão constituídas entre a formação do ACS e a sua articulação à ESF e aos processos de trabalho e de atenção à saúde. A qualificação deve ainda abordar os conhecimentos e habilidades necessários ao ACS e explicitar as implicações que o curso e a certificação trarão à vida pessoal e profissional, como sua acessibilidade social, o seu reconhecimento na comunidade como autoridade, vínculo profissional, direitos trabalhistas e remuneração. Esses preceitos garantem um processo de qualificação participativa que pode ser compreendida como uma estratégia fundamental para a cidadania (Melo et al., 2009; Morosini, 2010).

Na visão das gerentes das quatro UBS, apesar do curso exigir a ausência do ACS da unidade, trazendo consequências para o processo de trabalho, trouxe de maneira geral, um amadurecimento profissional e pessoal:

O curso foi muito interessante, ampliou a visão dos ACS que mais ativa, nas reuniões da equipe, contribuindo para a mudança ficaram muito envolvidos e procuraram cumprir todas as tarefas.

O curso contribuiu com o crescimento e amadurecimento dos ACS, incentivou a participação frente à equipe e à comunidade. A partir do curso os ACS tiveram maior interesse em se apropriar da teoria e se qualificar.

Observou-se que os gestores investigados reconhecem as possibilidades que a formação profissional do
ACS traz para a qualificação do processo de atenção à saúde, desde a ampliação da sua capacidade de produção, a minimização das relações sociais de dominação entre os diversos integrantes na ESF até o fortalecimento das probabilidades de transformação social. Não se pode negar que os saberes constituídos nesse espaço de formação amplia as possibilidades desses agentes de se tornarem sujeitos capazes de questionar e superar os limites impostos pela realidade da comunidade onde moram e trabalham.

\section{$\mathrm{DSC}_{4}$ - 0 programa promoveu mudanças em re- lação à vida pessoal do ACS}

Algumas mudanças provocadas pelo programa trouxeram implicações na vida pessoal do agente, entre elas a garantia de inserção e manutenção no mercado formal de trabalho, a inclusão social, a ascensão profissional e fonte salarial. Verificou-se a ampliação no percentual de carteiras de trabalho assinadas, em torno de 10,3\% após o curso. Em relação à renda, 51,7\% dos ACS tiveram aumento na faixa salarial. Esses avanços conquistados após o curso segundo relato dos ACS investigados, propiciaram melhores condições de vida.

De uma maneira geral, os trabalhadores convivem, atualmente, com uma insegurança em relação à manutenção no mercado de trabalho, essa situação foi vivenciada pelos ACS durante o curso. Segundo os docentes do programa, apesar do evidente interesse dos ACS em aprender, se profissionalizar e conquistar um certificado de técnico, a possibilidade de sua avaliação do curso, trouxe certo temor aos ACS, dessas se constituírem como parâmetros para possíveis demissões, o que levou os docentes a trabalharem essa situação. Segundo o discurso vigente, foi relatado um caso de reprovação no programa devido ao déficit cognitivo e o ACS continua exercendo a sua função. Entretanto, o medo foi superado pela motivação promovida pelo programa no sentido de buscar melhor formação e qualificação profissionais. Alguns ACS relataram o ingresso em cursos técnicos e de graduação, mesmo antes da conclusão do programa:

O curso ocasionou uma expectativa de ascensão profissional e salarial. Muito deles saíram para fazer faculdades para fazer outras coisas melhores. 
Assim que eu terminei o curso eu terminei meus estudos e corri atrás pra mim qualificar, teve muita gente que se formou aqui e o curso impulsionou isso também, eu formei em Administração.

As perspectivas de formação e aprimoramento profissionais despertadas pelo Programa foram corroboradas pelos docentes e ACS, como possibilidade de outras oportunidades e regaste da cidadania a partir da elaboração de planos pessoais de acessibilidade social (Melo et al., 2009).

\section{DSC $_{5}$ - 0 curso não promoveu mudanças... precisa mudar algumas coisas...}

O discurso o curso não promoveu mudanças vem confirmar os desafios intimamente relacionados ao processo de formação e qualificação dos ACS. A formação desse profissional se defronta, permanentemente, com a necessidade de ressignificar o processo de trabalho no âmbito da APS e assume uma centralidade ao abordar o cuidado em saúde. A posição ocupada por esse trabalhador na equipe gera conflitos, fato que exige reconhecimento e reflexão no Programa:

Eu acho que o que a gente viu lá a gente já fazia, não teve tanta novidade pelo fato da gente já tá no campo de trabalho já fazendo, a gente já tinha a prática. Deveria tervindo quando a gente começou. A maioria das coisas que a gente aprendeu no curso a gente não usa. A gente foi lá só aprender a teoria, aprimorar o conhecimento.

O discurso que a qualificação não promoveu nenhum tipo de mudança esteve apoiado na concepção que os ACS já traziam consigo vivências e experiências que os "habilitavam" adequadamente para o serviço, uma vez que já trabalhavam na estratégia de saúde da família há muitos anos. Esse discurso denota o valor que o ACS dá à dimensão experimental para a qualificação da sua prática, realçando que basta um conhecimento prévio. Realça, também, o pequeno valor da dimensão conceitual e social do programa, além de tornar o trabalhador um mero reprodutor de práticas (Ramos, 2001). Nessa condição, o ACS corre o risco de se defrontar com determinada realidade e, por sua capacidade de reflexão muitas vezes engessada, não conseguir transformá-la. Faz-se necessário, então, desvendar as necessidades de formação e qualificação do ACS baseadas no tipo de atribuição que esse profissional deve desenvolver não somente no âmbito técnico, mas também, ético, político e social. Entretanto, pode-se reconhecer a sua importância quando ocorreu a sugestão para que o curso fosse realizado no momento do ingresso do profissional no serviço.

Autores como Bornstein e Stotz (2008) alertam que a ênfase na teoria e na técnica pedagógica pode não contemplar a realidade histórica, cultural, social e política da maneira como deveriam. Especialmente, em um país de características geográficas e diversidades sociais tão complexas como o Brasil, propiciando a existência de lacunas de conhecimento na formação e qualificação dos trabalhadores da saúde que, consequentemente, podem favorecer a fragilização das práticas em saúde. Essa situação, entre outras, tem induzido as instituições gestoras e de pesquisa a formular e implementar mecanismos de avaliação da ação educativa para identificar os limites dessa atividade e buscar estratégias de reestruturação.

Um dos requisitos esperados pelos ACS e ESF era de que o curso trabalhasse mais a compreensão da área de atuação pelo ACS, demonstrando a necessidade de uma melhor abordagem da dimensão social do trabalho do agente pelo curso. Outro requisito parece esperar um treinamento de como atender uma demanda excessiva e se portar diante das dificuldades geradas pelas cobranças indevidas da comunidade. Essas duas situações não podem ser solucionadas a partir de ações prescritivas, mas com base em concepções teóricas e técnicas pautadas na ética.

Outra ponderação dos ACS e da equipe é sobre a necessidade de uma proposta de educação continuada semestral ou anual no âmbito da promoção da saúde, pois eles são capazes de fazer, só precisa qualificar mais, ter mais treinamento. Essa concepção traz em sua essência a ideia de alunos que são submetidos a adestramentos de técnicas, situação extremamente frágil diante de um campo complexo como da promoção da saúde que tem como pilares a interdisciplinaridade e a intersetorialidade pautados por um compromisso social de melhores condi- 
ções de vida e saúde. Nessa perspectiva, evidencia-se que o engajamento na esfera da promoção da saúde já é um ato complexo que exige o conhecimento do contexto dessa ação educativa e determinação ético-política. O sujeito que se propõe a trabalhar nessa linha necessita ter estimulada a sua capacidade de observação, reflexão e análise crítica sobre o contexto social que pretende transformar.

Nessa direção, a equipe e de alguns ACS afirmaram que o conteúdo didático do curso deveria privilegiar a realidade vivenciada pelos ACS em seu cotidiano de trabalho, subsidiados pelos princípios e diretrizes da Política Nacional de Educação Permanente em Saúde (Brasil, 2004). Na visão de Ceccim e Feuerwerker (2004), a educação Permanente em saúde, exige a interação do ensino com a gestão, a atenção em saúde e o controle social, que compõem o quadrilátero da formação em saúde. Suas quatro faces estabelecem entre si uma relação dialógica, não hierárquica. E como já discutido anteriormente, essa interação ainda não ocorre, visto que os usuários não têm conhecimento da existência do curso e não participa das ações relacionadas a ele. Associa-se, ainda um discurso relacionado à ESF e aos ACS sobre a necessidade de criação de espaços no programa para os diversos sujeitos envolvidos no processo de atenção à saúde no âmbito da APS:

espaços de discussão sobre a ação profissional não só do ACS, mas da equipe, pois a sobrecarga de trabalho na UBS impede a abertura desses espaços, por isso a própria qualificação deveria abrir este tipo de espaço e indicar a importância desses espaços de discussão na equipe para se trabalhar mais o SUS.

A equipe de pesquisadores compreendeu que essa estratégia é fundamental quando se pretende trabalhar a prática em saúde na sua totalidade, além de abrir possibilidades de corresponsabilização entre os diversos atores envolvidos. Evita-se, dessa forma, a centralização das funções em uma determinada categoria profissional e a excessiva delegação de ações ao ACS, que por força de determinantes históricos e sociais, apresentam-se geralmente submissos aos anseios da equipe e da comunidade, cobrindo inúmeras lacunas. Esse espaço constituiria, então, lugar de interlocução entre diferentes sujeitos visando uma produção de conhecimento baseada na pró-atividade e na autonomia do conjunto - ACS, usuário, equipe de saúde da família e gestão UBS. Trata-se da possibilidade de se debater diferentes saberes e associá-los às demandas e necessidades em saúde para proceder um planejamento participativo. Essa proposição reconhece a importância de consolidar o ACS como sujeito da ação - da construção conjunta de estratégias de resistência e de transformação das condições de saúde, no interior das especificidades de cada comunidade, equipe, grupo de ACS e da gestão.

Observou-se que os pesquisadores pareciam atribuir ao programa de qualificação responsabilidade única de desenvolver e aprimorar os instrumentos de trabalho do ACS e da equipe de saúde da família. Tal concepção permite entender que eles assumiriam a condição de assujeitados às ações advindas do Ministério ou das instituições formadoras e não adotariam a posição de protagonistas, a partir da riqueza de suas experiências e vivências, como sujeitos das práticas em saúde.

Outra necessidade a ser trabalhada no programa de qualificação apontada no discurso das equipes foi a dificuldade do ACS em separar a sua condição de morador da comunidade da sua de profissional, eles não conseguem se desligar dos problemas da comunidade e se envolvem muito, essencialmente, no seu despreparo para lidar com o usuário, portador de doenças crônicas e seus familiares, que demandam muito. Salienta-se que esse sofrimento é inerente a ação do ACS, o que amplia o valor da sua ação, pois o ato de se defrontar com a pluralidade da realidade cotidiana e comprometer-se com a vida das pessoas e questões que envolvem a comunidade em geral, consequentemente, despertará um sentimento de impotência. 0 curso poderia trabalhar essa situação criando espaços para grupos operativos com profissionais do campo da saúde mental e da escuta privilegiada.

Uma das equipes reconheceu o valor do curso e sinalizou que os problemas não são relativos ao curso e estão vinculados à equipe e ao próprio ACS. Realçam que alguns ACS não têm interesse no trabalho que realizam e, não conseguem captar a importância do curso ou ser sensibilizado por ele. 
Essa equipe sinaliza, ainda, a necessidade do curso sensibilizar o ACS quanto ao seu compromisso e responsabilidade. Entretanto, evidenciou-se um clima pouco ameno nessa equipe que demonstrou problemas de interação. Diante dessa situação constatou-se também a necessidade de implicar a equipe como um todo em alguns momentos desta qualificação para trabalhar esses conflitos.

A partir desse panorama afirma-se que o programa de qualificação investigado trouxe implicações favoráveis ao processo de atenção à saúde e na vida profissional e pessoal do ACS. Esses profissionais convivem com limitações do programa, não estruturado no referencial da educação permanente em saúde, o que favorece a manutenção de lacunas nas práticas em saúde e seus frágeis referenciais teóricos em relação ao campo da saúde coletiva. Outro ponto é a não inclusão de todos os sujeitos envolvidos no processo de atenção em saúde em momentos específicos do programa. Isso seria importante dentro de uma perspectiva participativa e democrática do quadrilátero de formação em saúde proposta por Ceccim e Feuerwerker (2004) e de ampliação das possibilidades dos espaços de discussão na estrutura do curso e no cotidiano laboral.

Apesar dos limites apresentados pela análise deste programa de qualificação, é possível observar nos discursos acima, que as questões trabalhadas no curso estão muito próximas da realidade cotidiana laboral dos Agentes Comunitários de Saúde investigados.

\section{Considerações finais}

Identificou-se no discurso dos sujeitos da pesquisa ancoragens ao modelo biomédico e o distanciamento da perspectiva participativa e democrática de todos os envolvidos no processo de atenção à saúde. Isso sinalizou a influência do contexto histórico, político, social e de concepções que motivaram o movimento da Reforma Sanitária no Brasil nos diversos discursos produzidos. Entretanto, o conjunto desses discursos não invalida ou diminui o impacto do curso de qualificação na vida profissional e pessoal desses profissionais. As transformações decorrentes do curso, presentes no discurso do sujeito coletivo, nos remetem ao processo de educação como instrumento de inclusão social e cidadania.

Quando se tem o trabalho como princípio educativo, investir na qualificação é uma estratégia para assegurar uma reflexão crítica sobre o processo de trabalho, o referencial teórico que dá suporte para a sua realização, a corresponsabilização dos diversos sujeitos envolvidos, a legitimação das práticas possíveis àquele contexto, as especificidades de cada ator social envolvido e o contexto a qual a ação educacional é voltada.

Em síntese, a qualificação dos ACS para um campo tão complexo e diverso como o da saúde no Brasil, implica em uma concepção com um referencial teórico baseado no campo da Saúde Coletiva e da EPS, menos técnica e mais problematizadora com base em princípios emancipatórios, éticos e políticos. Visto que pretende-se inspirar uma nova postura perante o seu fazer laboral que viabilize a transformação da realidade em saúde. Dessa maneira, não se concebe a prescrição presente na Lei $n^{0}$ 10.507 (Brasil, 2002) de uma "qualificação básica" para o ACS, extremamente frágil diante do significado social do Sistema Único de Saúde.

\section{Referências}

BARALHAS, M.; PEREIRA, M. A. O. Concepções dos agentes comunitários de saúde sobre suas práticas assistenciais. Physis: Revista de Saúde Coletiva, Rio de Janeiro, v. 21, n. 1, p. 31-46, 2011.

BEZERRA, A. F. B.; SANTO, A. C. E.; BATISTA FILHO, M. Concepções e práticas do agente comunitário na atenção à saúde do idoso. Revista de Saúde Pública, São Paulo, v. 39, n. 5, p. 809-815, 2005 .

BORNSTEIN, V. J.; MATTA, G. C.; DAVID, H. O processo de trabalho do agente comunitário de saúde e sua incidência sobre a mudança do modelo de atenção em saúde. In: MONKEN, M.; DANTAS, A. V. Estudos de politecnia e saúde. Rio de Janeiro: Epsjv, 2009. v. 4, p. 191-219.

BORNSTEIN, V. J.; STOTZ, E. N. Concepções que integram a formação e o processo de trabalho dos agentes comunitários de saúde: uma revisão de literatura. Ciência e Saúde Coletiva, Rio de Janeiro, v. 13, n. 1, p. 259-268, 2008. 
BRASIL. Decreto n. ${ }^{0} 3.189$, de 4 de outubro de 1999. Fixa diretrizes para o exercício da atividade de Agente Comunitário de Saúde (ACS), e dá outras providências. Diário Oficial da União, Brasília, DF, 5 out. 1999. Disponível em: <http:// www.planalto.gov.br/ccivil_o3/decreto/D3189. htm>. Acesso em: 15 dez. 2013.

BRASIL. Portaria n. ${ }^{\circ} 1298$, de 28 de novembro de 200o. Institui a Rede de Escolas Técnicas e Centros Formadores vinculados às instâncias gestoras do Sistema Único de Saúde (RET-SUS).

Diário Oficial da União. Brasília, DF, 29 nov. 2oooa. Disponível em: <http://www.jusbrasil.com. br/diarios/1523992/pg-58-secao-1-diario-oficial-dauniao-dou-de-29-11-200o>. Acesso em: 23 dez. 2014.

BRASIL. Ministério da Saúde. Secretaria de Políticas de Saúde. Departamento de Atenção Básica. $O$ trabalho do agente comunitário de saúde. Brasília, DF; 2ooob.

BRASIL. Lei n. ${ }^{0}$ 10.507, de 10 de julho de 2002. Cria a Profissão de Agente Comunitário de Saúde e dá outras providências. Diário oficial da União, Brasília, DF, 11 jul. 2002. Disponível em: <http:// www.jusbrasil.com.br/diarios/617811/pg-1-secao-1diario-oficial-da-uniao-dou-de-11-07-2002>. Acesso em: 5 jan. 2015 .

BRASIL. Portaria n. ${ }^{0}$ 198, de 13 de fevereiro de 2004. Institui a Política Nacional de Educação Permanente em Saúde como estratégia do Sistema Único de Saúde para a formação e o desenvolvimento de trabalhadores para o setor e dá outras providências. Diário Oficial da União, Brasília, DF, 16 fev. 2004. Disponível em: <http:// dtr2001.saude.gov.br/sas/PORTARIAS/Port2004/ GM/GM-198.htm>. Acesso em 11 out. 2013.

BRASIL. Portaria n. ${ }^{\circ}$ 2970, de 25 de novembro de 2009. Institui a Rede de Escolas Técnicas do SUS e dispõe sobre as diretrizes para a sua organização. Diário Oficial da União, Brasília, DF, 26 nov. 2009. Disponível em: <http://bvsms.saude.gov.br/bvs/ saudelegis/gm/2009/prt2970_25_11_2009.html>. Acesso em: 10 jun. 2013.
CECCIM, R. B.; FEUERWERKER, L. C. M. O quadrilátero da formação para área da saúde: ensino, gestão, atenção e controle social. Physis: Revista de Saúde Coletiva, Rio de Janeiro, v. 14, n. 1, p. 41-65, 2004.

CECÍlIO, L. C. O. As necessidades de saúde como conceito estruturante na luta pela integralidade e equidade na atenção em saúde. In: PINHEIRO, R.; MATTOS, R. A. (Org.). Os sentidos da integralidade na atenção e no cuidado de saúde. Rio de Janeiro: IMS,Uerj: Abrasco, 2001. p. 113-126.

FREIRE, P. Os cristãos e a libertação dos oprimidos. Lisboa: Edições Base, 1978.

FRIGOTTO, G. Fundamentos científicos e técnicos da relação trabalho e educação no Brasil de hoje. In: LIMA, J. C. F; NEVES, L. M. W. (Org.). Fundamentos da educação escolar do Brasil contemporâneo. Rio de Janeiro: Fiocruz, 2006. p. 241-289.

GOMES, K. O. et al. O agente comunitário de saúde e a consolidação do Sistema Único de Saúde: reflexões contemporâneas. Physis: Revista de Saúde Coletiva, Rio de Janeiro, v. 20, n. 4, p. 11431164, 2010.

KLUTHCOVSKY, A. C. G. C. et al. Avaliação da qualidade de vida geral de agentes comunitários de saúde: a contribuição relativa das variáveis sociodemográficas e dos domínios da qualidade de vida. Revista Psiquiatria Rio Grande Sul, Porto Alegre, v. 29, n. 2, p. 176-183, 2007.

\section{LEFÈVRE, F.; LEFÈVRE, A. M. C. $O$ discurso do} sujeito coletivo: uma abordagem metodológica. Caxias do Sul: Educs, 2005.

LIMA, M. A. D. S. et al. Acesso e acolhimento em unidades de saúde na visão dos usuários. Acta Paulista de Enfermagem, São Paulo, v. 20, n. 1, p. 12-17, 2007.

LOTTA, G. S. Saberes locais, mediação e cidadania: o caso dos agentes comunitários de saúde. Saúde e Sociedade, São Paulo, v. 21, p. 210-222, 2012.

Suplemento 1.

MELO, M. B. et al. Qualificação de agentes comunitários de saúde: instrumento de inclusão social. Trabalho, Educação e Saúde, Rio de Janeiro, v. 7, n. 3, p. 463-477, 2009. 
MERHY, E. E. Em busca da qualidade dos serviços de saúde: os serviços de porta aberta para a saúde e o modelo tecnoassistencial em defesa da vida. In: CECÍlIO, L. C. O. (Org.). Inventando a mudança em saúde. São Paulo: Hucitec, 1994. p. 116-16o.

MERHY, E. E. Em busca do tempo perdido: a micropolítica do trabalho vivo em saúde. In: MERHY, E. E.; ONOCKO, R. (Org.). Agir em saúde: um desafio para o público. 3. ed. São Paulo: Hucitec, 2007. p. 71-111.

MONTEIRO, M. A. G. S.; PREVITALI, F. S. A política de formação profissional dos agentes comunitários de saúde: limites e possibilidades de construção de sujeitos críticos. Revista Labor, Fortaleza, v. 1, n. 5, p. 141-163, 2011.

MOROSINI, M. V. Educação e trabalho em disputa no SUS: a política de formação dos agentes comunitários de saúde. Rio de Janeiro: Epsjv, 2010.

NOGUEIRA, R. P. 0 trabalho do agente comunitário de saúde: entre a dimensão técnica "universalista" e a dimensão social "comunitarista". Interface: Comunicação, Saúde, Educação, Botucatu, v. 6, n. 10, p. 91-93, 2002.
PAIM, J. S.; ALMEIDA FILHO, N. A crise da saúde pública e a utopia da saúde coletiva. Salvador: Casa da Qualidade, 2000.

RAMOS, M. N. Qualificação, competências e certificação: visão educacional. Formação, Presidente Prudente, v. 1, n. 2, p. 5-16, 2001. Disponível em: <http://bvsms.saude.gov.br/bvs/ publicacoes/profae/Revista2002.pdf\#page=19>. Acesso em: 23 dez. 2014.

RAMOS, M. N. Trabalho, educação e correntes pedagógicas no Brasil: um estudo a partir da formação dos trabalhadores técnicos da saúde. Rio de janeiro: Epsjv: Ufrj, 2010.

SANTOS, K. T. et al. Agente comunitário de saúde: perfil adequado a realidade do programa Saúde da Família? Ciência e Saúde Coletiva, Rio de Janeiro, v. 16, p. 1023-1028, 2011. Suplemento 1.

TOMAZ, J. B. C. O agente comunitário de saúde não deve ser um super-herói. Interface: Comunicação, Saúde, Educação, Botucatu, v. 6, n. 10, p. 75-94, 2002.

\section{Contribuição dos autores}

Melo realizou a coleta e análise de dados, revisão bibliográfica, elaboração e redação do artigo e revisão crítica do conteúdo. Quintão e Carmo realizaram a coleta e análise de dados e revisão crítica do conteúdo.

Recebido: 13/06/2013

Aprovado: $28 / 11 / 2013$ 